\title{
A new aerosol collector for quasi on-line analysis of particulate organic matter: the Aerosol Collection Module (ACM) and first applications with a GC/MS-FID
}

\author{
T. Hohaus ${ }^{1}{ }^{*}$, D. Trimborn ${ }^{2}$, A. Kiendler-Scharr ${ }^{1}$, I. Gensch ${ }^{1}$, W. Laumer ${ }^{1}$, B. Kammer ${ }^{1}$, S. Andres ${ }^{1}$, H. Boudries ${ }^{3}$, \\ K. A. Smith ${ }^{3}$, D. R. Worsnop ${ }^{2}$, and J. T. Jayne ${ }^{2}$ \\ ${ }^{1}$ Institut für Energie und Klimaforschung - Troposphäre (IEK-8), Forschungszentrum Jülich GmbH, Jülich, Germany \\ ${ }^{2}$ Aerodyne Research Inc., Billerica, MA, USA \\ ${ }^{3}$ Massachusetts Institute of. Technology, Cambridge, MA, USA \\ "now at: Aerodyne Research, Inc, Billerica, MA, USA
}

Received: 8 February 2010 - Published in Atmos. Meas. Tech. Discuss.: 31 March 2010

Revised: 23 July 2010 - Accepted: 6 October 2010 - Published: 12 October 2010

\begin{abstract}
In many environments organic matter significantly contributes to the composition of atmospheric aerosol particles influencing its properties. Detailed chemical characterization of ambient aerosols is critical in order to understand the formation process, composition, and properties of aerosols and facilitates source identification and relative contributions from different types of sources to ambient aerosols in the atmosphere. However, current analytical methods are far from full speciation of organic aerosols and often require sampling times of up to one week. Offline methods are also subjected to artifacts during aerosol collection and storage.
\end{abstract}

In the present work a new technique for quasi on-line compound specific measurements of organic aerosol particles was developed. The Aerosol Collection Module (ACM) focuses particles into a beam which is directed to a cooled sampling surface. The sampling takes place in a high vacuum environment where the gas phase from the sample volume is removed. After collection is completed volatile and semi-volatile compounds are evaporated from the collection surface through heating and transferred to a detector.

For laboratory characterization the ACM was interfaced with a Gas Chromatograph Mass Spectrometer, Flame Ionization Detector system (GC/MS-FID), abbreviated as ACM GC-MS. The particle collection efficiency, gas phase transfer efficiency, and linearity of the ACM GC-MS were determined using laboratory generated octadecane aerosols. The ACM GC-MS is linear over the investigated mass range of

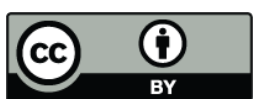

Correspondence to: A. Kiendler-Scharr (a.kiendler-scharr@fz-juelich.de)
10 to $100 \mathrm{ng}$ and a recovery rate of $100 \%$ was found for octadecane particles.

The ACM GC-MS was applied to investigate secondary organic aerosol (SOA) formed from $\beta$ pinene oxidation. Nopinone, myrtanal, myrtenol, 1hydroxynopinone, 3-oxonopinone, 3,7-dihydroxynopinone, and bicyclo[3,1,1]hept-3-ene-2-one were found as products in the SOA. The ACM GC-MS results are compared to quartz filter samples taken in parallel to the ACM GC-MS measurements. First measurements of ambient atmospheric aerosols are presented.

\section{Introduction}

Numerous techniques for the analysis of the chemical composition of organic aerosols (OA) exist. The complexity of $\mathrm{OA}$ and SOA due to the sheer number of individual compounds present (Goldstein and Galbally, 2007) is a major obstacle in the complete speciation of OA.

The most common methods of chemical speciation are filter-based techniques where particles are collected on quartz fiber or teflon filters. After sampling the filter content is analyzed in the laboratory using standard analytical procedures. These include a combination of solvent extraction, supercritical fluid extraction or thermal desorption of the filter samples with subsequent analysis with analytical techniques, such as gas chromatography coupled to mass spectrometry (GC-MS, most widely used) and liquid chromatography coupled to MS (LC-MS) (especially for polar compounds) to characterize the molecular composition of the OA. Pre-treatment of the filters, such as derivatization, can

Published by Copernicus Publications on behalf of the European Geosciences Union. 
be used to increase the range of measurable compounds. Recent studies showed improvements of the resolution of such techniques by using two-dimensional GC coupled to time-offlight (TOF) MS (Hamilton et al., 2004). The high quantities needed for laboratory analysis of filter samples often require sampling for several hours or days. Off-line time integrating bulk measurements are often subjected to positive and negative storage artifacts, such as loss of compounds due to volatilization, gas phase adsorption and reactions during collection that can alter the sample (Turpin et al., 2000).

In recent years instruments which utilize the concept of collecting particle samples on an impaction surface followed by desorbtion and mass spectrometric analysis of the sample were developed by a number of groups (e.g. Tobias et al., 2000; Williams et al., 2006). The Thermal Desorption Particle Beam Mass Spectrometer (TDPBMS) (Tobias et al., 2000) focuses particles in an aerodynamic lens with subsequent sampling in a high vacuum chamber on a cooled impaction surface. In the TDPBMS the particles are temperature-programmed thermally desorbed and analyzed using a quadrupole mass spectrometer. In a recent study another type of aerosol collector (Thermal Desorption Aerosol GC/MS-FID (TAG)) with $1 \mathrm{~h}$ time resolution has been presented by Williams et al. (2006). The TAG system collects aerosols, including both gas and particle phase of the aerosols, on an impaction surface which are subsequently thermally desorbed and analyzed by compound separation using a GC and subsequent analysis with a MS detector. While these approaches utilize higher sample flows than the ACM described herein, none of the instruments was developed to be compatible with a range of different detectors.

The types of sampling described before have limitations regarding the temporal sampling densities. Therefore today an important focus lies on the on-line measurements of aerosol chemical composition in real time with high time resolution. Two main types of on-line techniques are widely used, the thermal vaporization aerosol mass spectrometer (AMS) and the particle-into-liquid sampling (PILS). The most commonly used version of the AMS vaporizes the sampled aerosol on a hot surface under vacuum condition with subsequent detection of the ions using EI ionization and mass spectrometry. The AMS provides quantitative measurements of the mass concentration of aerosol constituents and size distributions in real time. However due to the mass spectral complexity, particularly for organic species, it is generally impossible for the AMS to identify individual organic compounds in ambient aerosol. The PILS utilizes automated ion chromatography to quantify the average bulk aerosol ionic composition (Weber et al., 2001). It provides quantitatively continuous measurement of the major inorganic and organic anions and cations with a time resolution of a few minutes depending on the selection of columns and eluants used. For a complete overview the reader is referred to a number of reviews published in the last years (McMurry, 2000; Rudich et al., 2007; Canagaratna et al., 2007; Hallquist et al., 2009).

\section{Instrumental description}

Within the present work a new technique for quasi online compound specific measurements was developed: the Aerosol Collection Module coupled to GC/MS-FID (ACM GC-MS). The Aerosol Collection Module (ACM) is designed to sample atmospheric aerosol and transfer the evaporated volatile and semi-volatile constituents of the particle sample to a gas phase detector. In practice, collection is achieved in a high vacuum environment on a cooled (maximum $-165^{\circ} \mathrm{C}$ ) collection surface. After collection is completed a carrier gas is introduced into the collector and the semi-volatile constituents of the particles are thermally desorbed by heating the collection surface to a preset temperature (maximum $350{ }^{\circ} \mathrm{C}$ ). The compounds are transferred by the carrier gas through a transfer section and injected into a gas phase detector. The ACM can be operated with a variety of carrier gases (e.g. He, $\mathrm{H}_{2}, \mathrm{~N}_{2}$ ) often determined by the type of gas phase detector coupled to the ACM. Therefore, in difference to similar techniques such as the TAG presented by Williams et al. (2006), only the particle phase of the aerosols can be analyzed without interference of the gas phase constituents. A schematic of the ACM is shown in Fig. 1. The ACM consists of three main sections: a particle focusing section, a particle collection section and a transfer section. Each section of the ACM is described in detail in the following.

\subsection{Particle sampling}

The sample introduction system and the vacuum system are of a same design as for the Aerodyne aerosol mass spectrometer (AMS) (Jayne et al., 2000) and are only briefly summarized here. The particle focusing section consists of two parts, an aerodynamic lens system (Liu et al., 1995a,b) which is coupled to a vacuum system. Aerosols are sampled through a critical orifice with a diameter of $100 \mu \mathrm{m}$ into an aerodynamic lens. Due to the critical orifice mounted at the aerosol inlet the pressure inside the lens is fixed approximately at $2.6 \mathrm{hPa}$. Inside the lens the particles are focused into a narrow beam while gas phase species are removed from the sample volume. The particle transmission efficiency of the ACM inlet compares to the transmission efficiency of the Aerodyne AMS inlet. The transmission efficiency ranges from $50 \%$ for $70 \mathrm{~nm}$ particles to $100 \%$ for the size range of $100 \mathrm{~nm}-500 \mathrm{~nm}$ particles and is $30 \%$ for $1 \mu \mathrm{m}$ particles (Liu et al., 2007). The vacuum system consists of three differentially pumped vacuum chambers. Turbo pumps 1 and 2 are separated by a skimmer and turbo pumps 2 and 3 are separated by a $0.3175 \mathrm{~cm} \times 2.032 \mathrm{~cm}$ channel aperture. A turbomolecular pump (Varian Turbo-V 301 Navigator Pump) is used to evacuate the first vacuum chamber. The pressure in this chamber is maintained below $10^{-3} \mathrm{hPa}$ which ensures a constant flow $\left(1.4 \mathrm{~cm}^{3} \mathrm{~s}^{-1}\right)$ through the aerodynamic lens. The second and third vacuum chambers are pumped with two 


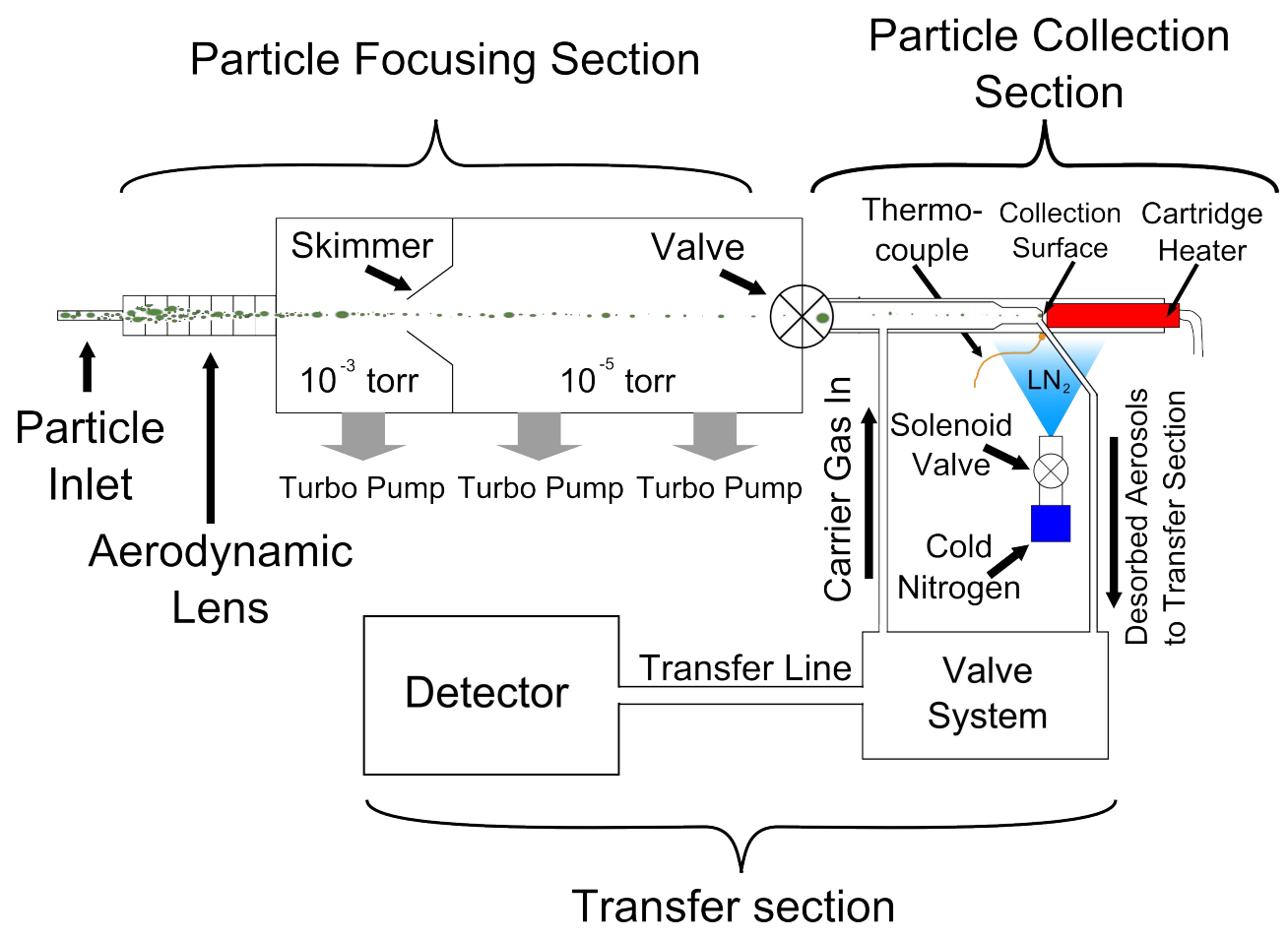

Fig. 1. Schematic of the ACM instrument. The ACM is composed of three main sections: the particle sampling section consisting of the aerodynamic lens and the vacuum system, the particle collection section including the collector and the cooling/heating system and the gasified particle transfer section which contains the valve system and the transfer line.

Varian Turbo-V 81 Pumps and maintained at a pressure below $10^{-5} \mathrm{hPa}$. The vacuum system can be separated from the collector with an automated controlled vacuum isolation valve to prevent carrier gas from compromising the vacuum and to prevent loss of volatile and semi-volatile compounds during desorption and transfer of the compounds to the detector.

\subsection{Particle collection}

The particle collection system of the ACM consists of a collector and a cooling/heating system. The collector is a stainless steel tubing with an inner diameter of $5.3 \mathrm{~mm}$ and a length of $80.8 \mathrm{~mm}$. After $43 \mathrm{~mm}$ the tubing tapers for $7 \mathrm{~mm}$ and ends at the collection surface which is approximately $3.4 \mathrm{~mm}$ in diameter. The particle focusing system is aligned in such a way that the focused particle beam passing the vacuum isolation valve is directed to the center of the sampling surface. The collector is chemically passivated with a Silcosteel ${ }^{\circledR}$ coating (SilcoTek, Bellefonte, PA). During sampling the collector can be cooled with nitrogen from a liquid nitrogen source. The nitrogen is sprayed towards the collector. The amount of nitrogen can be controlled through an automated solenoid valve. Hence the collection temperature can be kept constant during sampling with a maximum deviation of $\pm 5^{\circ} \mathrm{C}$ from the set temperature. A subzero temperature was chosen for all experiment presented in this study to reduce possible bouncing of the particles in the collector and the collection surface, respectively. On the back of the collector is a bore hole which holds a cartridge heater. The tip of the heater is centered $6.6 \mathrm{~mm}$ behind the collection surface and due to its position rapid heating and evaporation of the collected particle sample are assured. Two additional $1 / 16^{\prime \prime}$ tubings are connected to the collection section which are chemically passivated with Silcosteel ${ }^{\circledR}$ (SilcoTek, Bellefonte, PA). The first tube is located between the vacuum isolation valve and the collection surface. It introduces a carrier gas into the collector. The second tube is located directly below the sampling surface and connects the collector with the transfer section.

\subsection{Particle transfer}

The valve system used for sample transfer consists of two 4 port valves with $1 / 16^{\prime \prime}$ fittings and $0.75 \mathrm{~mm}$ ports (Valco Instruments Company Inc., Houston, TX) which are controlled by a microelectric actuator. A schematic of the valve system is shown in Fig. 2. The valves are connected with the collector and among each other with $1 / 16^{\prime \prime}$ stainless steel tubings.

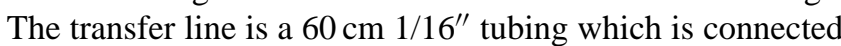
to the valve system at port 4 of valve 2 . The valve system and the transfer line can both be heated and kept at constant temperatures up to $300^{\circ} \mathrm{C}$. Both valves and the transfer line are chemically passivated with an Inertium ${ }^{\circledR}$ coating. The $1 / 16^{\prime \prime}$ 


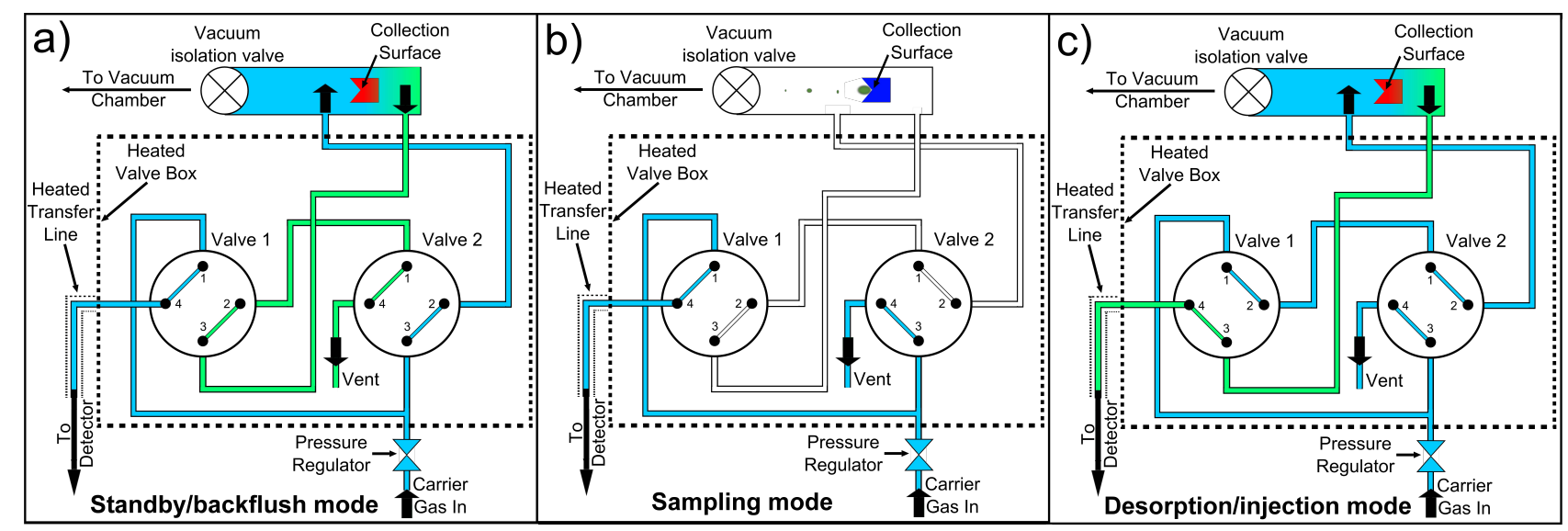

Fig. 2. (a) Standby/backflush mode: the collector and detector are supplied with the carrier gas. For cleaning purpose the collector can be heated (backflush mode). (b) Sampling mode: the collector is separated from the carrier gas supply and the particle beam is directed to the collection surface where the particle sample is accumulated. During sampling the collector is cooled with liquid nitrogen. (c) Desorption/injection mode: the vacuum isolation valve is closed and the collector heated. The particle sample is desorbed from the collection surface and transferred with the carrier gas stream to the detector.

tubings are passivated with Silcostee ${ }^{\circledR}$. In every experiment and set up presented here the carrier gas is helium with a minimum purity of $99.9999 \%$. The helium flow is pressure regulated at the entrance to the ACM and held constant at $2400 \mathrm{hPa}$. The valve settings for standby/backflush mode are shown in Fig. 2a. The carrier gas enters the ACM and is split into two streams. In standby mode stream one flows through valve 1 to the detector. Independent of the valve settings the detector was constantly provided with helium. The second stream flows through valve 2 into the collector, flushes over the collection surface, leaves the collector, passes through the two valves and leaves the system through a vent. A measurement cycle is started by cooling the collector with liquid nitrogen and keeping the collector at the desired collection temperature during the particle collection. As soon as the collector reaches the collection temperature valve 2 is switched. Thereby the collector is separated from the carrier gas. The entrance and the exit of the $1 / 16^{\prime \prime}$ tubing of the collector are now connected into a loop (Fig. 2b). The vacuum isolation valve opens and the collector and the loop are evacuated. The particle beam is directed to the collection surface where the particles impact upon. After the sampling is completed the vacuum isolation valve closes and valve 1 is switched (Fig. 2c). The carrier gas is introduced again into the collector. The cartridge heater is then heated at a preset temperature which can be set to a maximum temperature of $350^{\circ} \mathrm{C}$ and the volatile and semi-volatile compounds of the particle sample are desorbed from the collection surface. The carrier gas flushes the evaporated compounds through valve 1 into the transfer line and to the detector. After the desorption is completed valves 1 and 2 are switched back to their initial positions. The ACM enters the cleaning mode called backflush mode. The cartridge heater remains active and as a general rule is set in this stage to a higher temperature than the desorption temperature previously applied. Due to the higher temperature of the collector and therefore of the collection surface any volatile and semi-volatile residuals of the sampling are now desorbed and flushed out of the system through the vent passing both valves. This cleaning of the collector is performed after each measurement. The duration of the backflush mode can be set to meet the actual requirements regarding possible remaining contaminations. After the cleaning is completed the cartridge heater is powered down and the ACM is again in standby and ready for the next cycle.

\subsection{Detector}

The ACM is coupled to a detector where a quasi on-line analysis of the collected gasified particle can be conducted. It is possible to couple the ACM with different types of analytic gas detectors and thereby address different scientific questions without changing the type of sampling. The type of detector can be chosen in regard to the specific analytical abilities of the detectors, for example the chemical speciation of a sample using a gas chromatograph (GC) coupled with a mass spectrometer (MS) or the soft ionization capability of a proton transfer reaction mass spectrometer (PTR-MS). In this study the ACM was coupled with a combination of a gas chromatograph (Fisions GC8060) and a quadrupole mass spectrometer (Fisions MD800) operating with $70 \mathrm{eV}$ electron impact (EI) ionization. The GC-MS system consists of a cryofocusing module (Tekmar 3000) and an additional flame ionization detector (FID). An Agilent J\&W DB-5ms capillary column with $0.25 \mathrm{~mm}$ inner diameter, a film thickness of $0.25 \mu \mathrm{m}$ and a length of $60 \mathrm{~m}$ is installed in the gas chromatograph. The cool down of the cryo-focusing module (CFM) 

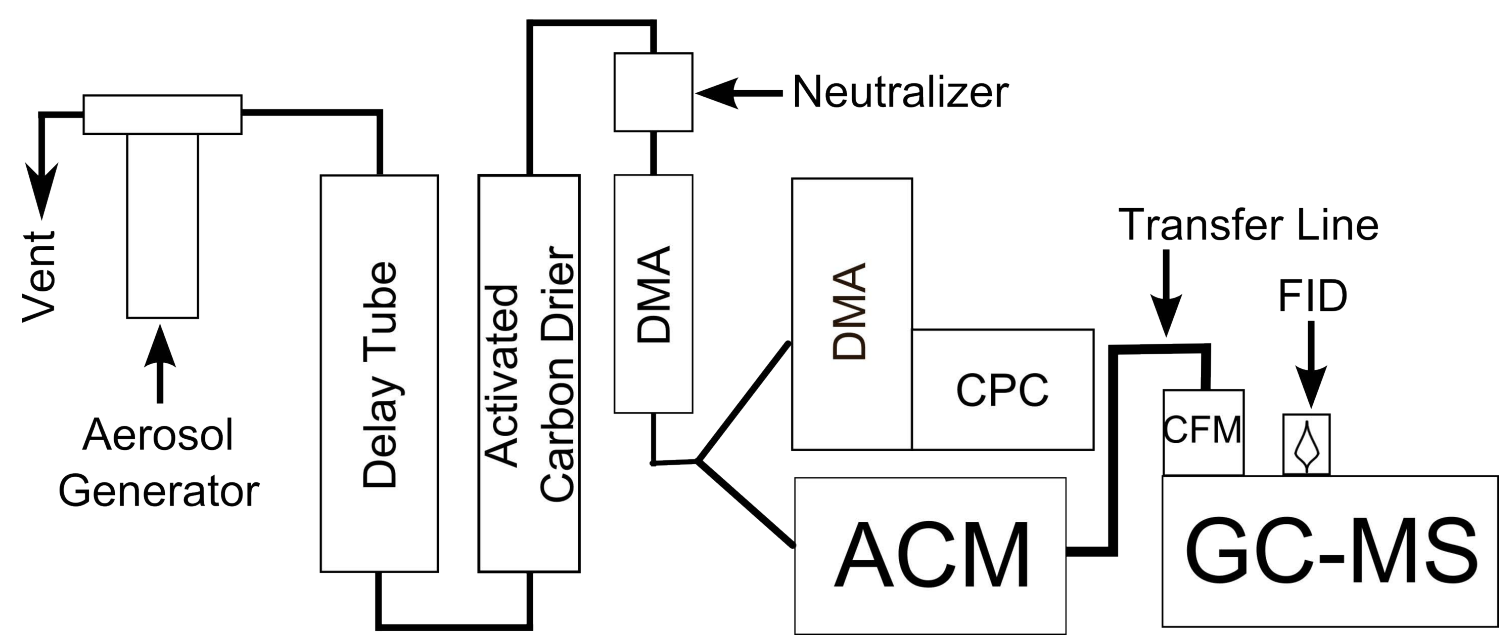

Fig. 3. Schematic of the experimental setup for measuring octadecane aerosols simultaneously with the ACM GC-MS and a SMPS. The aerosols are generated with an aerosol generator, dried, size selected and transferred to the two systems.

is started and reaches its final temperature during the ACM sampling. The particle sample desorbed from the ACM is refocused at the beginning of the GC column. One minute after desorption is completed the CFM is rapidly heated and the sample is injected into the GC for chromatographic separation. Compounds eluted from the column are split with a Ysplitter with a constant split ratio of 1:1 to be detected simultaneously with the FID and the MS. For all results presented the quantification was done using the ACM GC-FID measurements. The ACM GC-MS measurements were solely used for compound identification.

\section{Instrumental evaluation: methods}

In the following the methods used to characterize the ACM are presented. The performance of the GC-MS system was determined by direct injection of different compounds into the detector. Also the collection, desorption and transfer efficiency of octadecane test particles of the complete ACM GC-MS system was evaluated. Reproducibility and recovery rate of the collected particles were determined.

\subsection{GC-MS detector calibration}

The GC-MS system was calibrated with a homologous series of 14 alkanes from n-Heptane $\left(\mathrm{C}_{7} \mathrm{H}_{16}\right)$ to n-Eicosane $\left(\mathrm{C}_{20} \mathrm{H}_{42}\right)$, nopinone $\left(\mathrm{C}_{9} \mathrm{H}_{14} \mathrm{O}\right.$, NIST identifier: Bicyclo[3,1,1]heptan-2-one, 6,6-dimethyl-) and acetone. The substances were directly injected into the GC-MS using a $0.5 \mu \mathrm{l}$ syringe.

\subsection{ACM particle collection, desorption and transfer efficiency}

In Fig. 3 the experimental setup for producing and measuring octadecane aerosols with the ACM GC-MS is shown. Aerosols were generated with a TSI constant output aerosol generator (TSI 3076) from a solution of $0.5 \mathrm{~g}$ octadecane solved in $100 \mathrm{ml}$ ethanol. The aerosols were transferred to a delay tube and dried in an activated carbon drier. Thereafter the aerosols were size selected with a Differential Mobility Analyzer (DMA). The DMA voltage was kept constant so that only particles with a particle diameter of $250 \mathrm{~nm}$ were selected. After the size selection the aerosol flow was split to be characterized simultaneously with the ACM GC-MS and a Scanning Mobility Particle Sizer (SMPS) (TSI 3934). The time resolution, i.e. one complete scan of the size distribution of the SMPS, was 3 min. The sampling of the ACM was stopped matching the end of a completed scan of the SMPS. For all experiments the collection temperature of the $\mathrm{ACM}$ collector was $-30 \pm 5^{\circ} \mathrm{C}$. However the maximum desorption temperature was varied between $150^{\circ} \mathrm{C}$ and $270^{\circ} \mathrm{C}$ during these experiments to evaluate the temperature dependence of the desorption efficiency of particles from the collector. The temperature of the valve array and the transfer line were always matched with the desorption temperature. The desorption time, i.e. the time the collector was heated and the valve array was in the inject mode, was kept constant at $6 \mathrm{~min}$. The desorbed particles were then concentrated again in the cryofocusing module (CFM) at $-120^{\circ} \mathrm{C}$ for one more minute after the desorption was completed. Then the $\mathrm{CFM}$ was heated in $2 \mathrm{~min}$ to a temperature of $220^{\circ} \mathrm{C}$ and the sample was injected into the GC-MS for analysis. The GC program for this measurement was: oven temperature held at $50{ }^{\circ} \mathrm{C}$ for $5 \mathrm{~min}$; ramped at a rate of $10^{\circ} \mathrm{C} \mathrm{min}^{-1}$ to $220^{\circ} \mathrm{C}$; isothermal hold at $220^{\circ} \mathrm{C}$ for $8 \mathrm{~min}$. Note that during the GC-MS analysis a new sample collection can be started. 


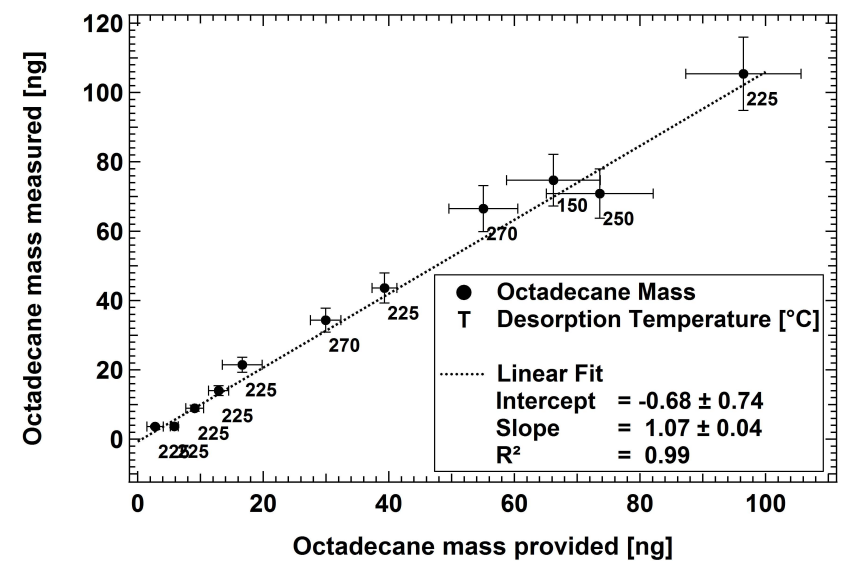

Fig. 4. Octadecane mass measured with the GC-FID vs. the collector loading (calculated from SMPS measurements) together with a linear fit through data points. Numbers show the desorption temperatures for each measurement.

\section{Instrumental evaluation: results}

\subsection{GC-MS detector calibration}

The GC-MS system was calibrated using direct injection of compounds ensuring linear response in a concentration range of 10 to $200 \mathrm{ng}$. For all compounds excellent linear responses with $R^{2}>0.93$ were obtained. The direct injection measurements are also used to verify the capability of the identification of compounds with the quadrupole mass spectrometer. The obtained mass spectra for each compound were compared with the EI spectra of the NIST library database. The comparisons achieve good results and the automatic search and compare algorithm of the MS data acquisition software (Masslab 1.4) identified all compounds with a reverse fit factor REV $>886$. REV indicates how likely it is that the obtained spectrum contains the library entry with REV $=1000$ being a perfect match.

\subsection{ACM particle collection, desorption and transfer efficiency}

A series of experiments was performed using different sampling times to vary the mass loadings on the ACM collector. The collector loading was calculated using the SMPS number size distribution. The number size distribution was converted into the volume of the particles. The total volume distribution was derived by integrating each SMPS scan. Since the entire SMPS distribution was used for the calculation of the ACM collector loading the contribution of doubly charged particles was accounted for. Due to the low vapor pressure of octadecane $\left(0.025 \mathrm{~Pa}\right.$ at $\left.20^{\circ} \mathrm{C}\right)$ it can be assumed that no vaporization losses occurred during the sampling of the octadecane particles. The mass introduced into the ACM was calculated using the following equation:

$M_{\mathrm{ACM}}=\overline{C_{V_{\mathrm{SMPS}}}} \times 10^{-21} \cdot \rho_{\mathrm{C}_{18} \mathrm{H}_{38}} \cdot f_{\mathrm{ACM}} \cdot t_{\mathrm{S}}$ where $M_{\mathrm{ACM}}$ is the ACM collector mass loading $(g), \overline{C_{V_{\mathrm{SMPS}}}}$ the average total particle volume concentration $\left(\mathrm{nm}^{3} \mathrm{~cm}^{-3}\right)$, $\rho_{\mathrm{C}_{18} \mathrm{H}_{38}}$ the density of octadecane $\left(0.777 \mathrm{~g} \mathrm{~cm}^{-3}\right), f_{\mathrm{ACM}}$ the sampling flow into the ACM $\left(1.42 \mathrm{~cm}^{3} \mathrm{~s}^{-1}\right)$ and $t_{\mathrm{S}}$ the sampling time $(s)$. The factor $10^{-21}$ accounts for the necessary conversion of the particle volume concentration and density to calculate the ACM collector mass loading in $g$. Note that within the limits of detection no impurities could be observed in the GC/MS-FID chromatogram for all octadecane particle measurements. The peaks of all octadecane samples in the GC-FID chromatogram measured with the ACM GCMS were integrated and the peak areas were converted into octadecane mass using the calibration of the GC-FID calibration measurements. Figure 4 shows the mass measured with the GC-FID versus the calculated mass loading from the SMPS data. The slope of the linear fit to the data is $1.06 \pm 0.04$.The recovery rate for octadecane is $100 \%$ within the measurement uncertainties. Additionally the desorption temperature was changed between $150^{\circ} \mathrm{C}$ and $270^{\circ} \mathrm{C}$ (numbers at each data point). The temperature of the valve array and the transfer line were changed accordingly to match the desorption temperature. Within this temperature range the octadecane is completely desorbed from the collector and transferred without losses to the GC-MS detector. Additionally no thermal degradation, impurities or artifacts resulting from the sampling or desorption of octadecane could be observed. It could be demonstrated that the ACM GC-MS response is linear over a mass range of 10 to $100 \mathrm{ng}$. The experiments with octadecane represent ideal performance since this compound is easily vaporized and has little thermal degradation. More complex and highly oxidized compounds may not yield transfer efficiencies as has been measured with octadecane.

\section{Secondary organic aerosol formation from $\beta$-pinene ozonolysis}

The ACM GC-MS was applied to measure secondary organic aerosol (SOA) from the oxidation of $\beta$-pinene with ozone in an atmosphere simulation chamber experiment. The SOA was measured and analyzed using SMPS, ACM GCMS measurements and filter samples.

\subsection{Description of the aerosol chamber of the FZJ}

The aerosol chamber of the Forschungszentrum Jülich (FZJ) was used for experiments characterizing SOA with the ACM GC-MS system and filter samples. The aerosol chamber has been described in detail elsewhere (Mentel and Wahner, 1996). Briefly, the aerosol chamber consists of an aluminium box. The inner walls are lined with chemically inert Fluorinated Ethylene Propylene (FEP) teflon foil. The FEP foil is permeable for gas and the interspace between the aluminium box and the foil is constantly flushed with pure synthetic air 
(minimum purity of $99.9999 \%$ ) to avoid contamination of the chamber. The chamber has a volume of $260 \mathrm{~m}^{3}$ and a surface of $250 \mathrm{~m}^{2}$. Thus the chamber has a surface to volume ratio of $0.96 \mathrm{~m}^{2} \mathrm{~m}^{-3}$. A small surface to volume ratio $(<1)$ minimizes potential wall loss such as deposition of aerosols or trace gases.

Homogenous mixing inside the chamber is achieved by convection. This is provided by a floor heating system which temperature periodically changed in the range of $30^{\circ} \mathrm{C} \pm 4^{\circ} \mathrm{C}$ over the duration of $2 \mathrm{~h}$. Thus the mixing time inside the chamber is less than $10 \mathrm{~min}$. The use of the floor heating results in a periodic temperature and relative humidity fluctuation in the chamber during the experiment by about $\pm 0.25^{\circ} \mathrm{C}$ and $\pm 2 \%$, respectively.

\subsection{Experimental conditions and procedure}

In the aerosol chamber experiment the formation of secondary organic aerosol (SOA) from the oxidation of $\beta$ pinene with ozone was studied. The experiment was conducted at ambient pressure and temperature. Prior to the experiment the chamber was flushed with particle free outside air for $16.5 \mathrm{~h}$. The humidity of the chamber was determined through the humidity of the outside air used for flushing the chamber. No additional humidification was applied. The initial conditions inside the chamber after flushing were $27 \%$ relative humidity, a temperature of $20^{\circ} \mathrm{C}$, and an ozone concentration of approximately $20 \mathrm{ppb}$. CPC measurements were used to check if the aerosol chamber was particle free. The particle concentration was $<20 \mathrm{~cm}^{-3}$.

Pure $\beta$-pinene (Aldrich, purity of $99 \%$ ) was introduced into the chamber as a liquid with a microliter syringe. $1 \mathrm{~mL}$ of $\beta$-pinene, equivalent to $584 \mathrm{ppbv}$, was injected in 10 steps through an opening in the chamber wall approximately $4 \mathrm{~m}$ above the chamber floor. After the contents of the chamber was well mixed $1 \mathrm{ppm}$ ozone was injected. The ozone was generated from pure oxygen with a minimum purity of 99.998\% through electrical discharges and introduced into the chamber with two inlets, one near a wall and the other at the center of the chamber.

Note that the initial monoterpene and ozone concentrations were two to three orders of magnitude above ambient levels (Guenther et al., 1995; Kesselmeier and Staudt, 1999). The high concentrations of the gas phase precursors were chosen in order to ensure sufficient aerosol mass for the experiment. An excess of ozone was used to ensure that all of the $\beta$-pinene is consumed during the experiment.

The hydroxyl radical chemistry occurring in the chamber is largely independent of the concentration regarding the chemical mechanism and the products formed (Atkinson, 1997). However, the high concentrations do have an influence on the relative importance of competing reactions of organic species with ozone, $\mathrm{OH}$ and $\mathrm{NO}_{\mathrm{x}}$. In this experiment no scavenger was used so that the oxidation of the precursor and to some extent of the products was due to ozone and $\mathrm{OH}$ radicals (Atkinson and Arey, 2003). The SOA composition was studied for $57 \mathrm{~h}$ in that experiment.

The particle number concentration was measured with a Condensation Paricle Counter (CPC) (TSI 3786) with a 50\% detection particle diameter of $3 \mathrm{~nm}$. The flow of the CPC was $600 \mathrm{~mL} \mathrm{~min}^{-1}$. The CPC was measuring continuously during the experiment.

The particle size distribution was measured with a Scanning Mobility Particle Sizer (SMPS) (TSI 3934). The time resolution of the SMPS system was set to $3 \mathrm{~min}$. The SMPS was measuring the number concentration of particles with diameters between $14 \mathrm{~nm}$ and $750 \mathrm{~nm}$. The sample flow of the SMPS system was $300 \mathrm{~mL} \mathrm{~min}^{-1}$. The SMPS was connected to the ACM GC-MS with a Y-splitter. The Y-splitter itself was connected to the chamber with a $1 \mathrm{~m}$ stainless steel sampling line.

During the experiment aerosol samples were taken regularly with the ACM GC-MS system. The collection time for each sample was $60 \mathrm{~min}$. The collection temperature of the collector was $-30^{\circ} \mathrm{C}$ and the desorption temperature $225^{\circ} \mathrm{C}$. The particle sample was desorbed for $6 \mathrm{~min}$ from the collector. The temperature of the valve array and the transfer line were kept constant at $230{ }^{\circ} \mathrm{C}$ to prevent re-condensation of gases onto valve and lines. The gasified particles were focused after desorption in the CFM for $1 \mathrm{~min}$ at $-120^{\circ} \mathrm{C}$ and injected into the GC-MS at $225^{\circ} \mathrm{C}$. The temperature program of the GC oven for each sample was as follows: start oven temperature was held at $40^{\circ} \mathrm{C}$ for $5 \mathrm{~min}$; ramped at a rate of $5^{\circ} \mathrm{C} \mathrm{min}^{-1}$ to $200^{\circ} \mathrm{C}$; isothermal hold at $200^{\circ} \mathrm{C}$ for $12 \mathrm{~min}$. The total GC run was $54 \mathrm{~min}$. With the desorption time of 6 min the total ACM GC-MS measuring cycle was $60 \mathrm{~min}$. After each desorption the ACM was operated in the backflush mode with a temperature of $250^{\circ} \mathrm{C}$ for $10 \mathrm{~min}$.

During the experiments aerosol filter samples were taken in parallel to the ACM GC-MS sampling. The aerosols were sampled on quartz fiber filters (Millipore, $47 \mathrm{~mm}$ diameter). The filters were preheated for $10 \mathrm{~h}$ at $600^{\circ} \mathrm{C}$ before sampling. The filter holders were connected to the chamber with a $1 \mathrm{~m}$ long stainless steel tubing. The sampling line of the filters was situated $3 \mathrm{~m}$ away from the ACM GC-MS sampling line. The flow through the filter was $25 \mathrm{~L} \mathrm{~min}^{-1}$ and was regulated with a mass flow controller (MKS Instruments, Type 579). After sampling the filters were stored in a $55 \mathrm{~mm}$ Petri dish, wrapped in aluminium foil, and stored in a freezer at $-18^{\circ} \mathrm{C}$ for later analysis.

In total 16 ACM GC-MS measurements with a $60 \mathrm{~min}$ sampling interval were taken over a time period of $57 \mathrm{~h}$ after starting SOA formation. Details of the ACM GC-MS and filter measurements are shown in Table 1. Prior to the injection of $\beta$-pinene a filter and ACM GC-MS sample were taken from the empty chamber. ACM GC-MS blank measurements (c.f. Sect. 5.6) were conducted regularly between the chamber samples. For the blank measurement a High Efficiency Particulate Air (HEPA) filter was installed between the chamber sampling tubing and the ACM GC-MS inlet. 
Table 1. Overview of the course of the $\beta$-pinene experiment and the samples collected with the ACM GC-MS and filter measurements. $t_{\mathrm{O}_{3}}$ is the time after ozone was injected into the chamber. $C_{\mathrm{O}_{3}}$ is the mixing ratio of ozone in the chamber. $M_{\mathrm{SOA}}$ is the total SOA mass inside the chamber. $\mathrm{S}$ indicates that a chamber sample is collected with the ACM GC-MS and in parallel with quartz filters and B indicates that a ACM GC-MS blank measurement was performed.

\begin{tabular}{rccl}
\hline$t_{\mathrm{O}_{3}}[\mathrm{~h}]$ & $C_{\mathrm{O}_{3}}[\mathrm{ppb}]$ & $M_{\mathrm{SOA}}\left[\mu \mathrm{g} \mathrm{m}^{-3}\right]^{\mathrm{a}}$ & Comment \\
\hline-2.12 & - & - & chamber blank measure- \\
& & & $\begin{array}{l}\text { ment S1 } \\
\text { injection of } 600 \mathrm{ppb} \beta- \\
\text { pinene }\end{array}$ \\
& - & - & injection of $1 \mathrm{ppm}$ ozone \\
0 & 872 & 0.01 & $\mathrm{~S} 2$ \\
1.3 & 730 & 650 & $\mathrm{~B} 1$ \\
3.03 & 546 & 870 & $\mathrm{~S} 3$ \\
4.77 & 499 & 827 & $\mathrm{~B} 2$ \\
6.47 & 476 & 821 & $\mathrm{~S} 4$ \\
8.05 & 465 & 744 & $\mathrm{~B} 3$ \\
9.82 & 449 & 726 & $\mathrm{~S} 5$ \\
21.97 & 390 & 476 & $\mathrm{~B} 4$ \\
23.57 & 385 & 473 & $\mathrm{~S} 6$ \\
25.03 & 382 & 449 & $\mathrm{~S} 7$ \\
26.55 & 372 & 438 & $\mathrm{~S} 8$ \\
28.12 & 368 & 414 & $\mathrm{~S} 9$ \\
29.72 & 361 & 391 & $\mathrm{~S} 10$ \\
31.32 & 356 & 388 & $\mathrm{~B} 5$ \\
32.68 & 346 & 367 & $\mathrm{~S} 11$ \\
46.03 & 312 & 282 & $\mathrm{~B} 6$ \\
47.52 & 308 & 265 & $\mathrm{~S} 12$ \\
49.05 & 307 & 252 & $\mathrm{~S} 13$ \\
50.60 & 299 & 247 & $\mathrm{~S} 14$ \\
52.12 & 294 & 238 & $\mathrm{~S} 15$ \\
53.63 & 294 & 233 & $\mathrm{~S} 16$ \\
55.12 & 291 & 220 & \\
56.62 & 282 & 216 & \\
\hline & & &
\end{tabular}

a calculated from the SMPS data using an average SOA density of $1.2 \mathrm{~g} \mathrm{~cm}^{-3}$

The same measurement cycle of the ACM GC-MS was repeated with the installed filter. The blank measurements were used to check for contaminations or residues inside the ACM GC-MS and for adsorptions from the gas phase onto the collector.

\subsection{Results of the ACM GC-MS measurements}

Figure 5 shows the first GC-FID chromatogram (sample S2) measured with the ACM GC-MS after the reaction in the chamber was started. The sample was taken 78 min after ozone injection. The FID chromatogram shows a variety of compounds. The majority of peaks are observed between 3 to $8 \mathrm{~min}$ and 15 to $33 \mathrm{~min}$ retention time. Two peaks, at $3.44 \mathrm{~min}$ and $25.3 \mathrm{~min}$ respectively, are the major products dominating the aerosol signal at this early stage in the reaction.

For the identification of the chromatographically separated compounds two approaches were used. The first approach was to identify the peaks by comparison of the mass spectra measured with the MS with the content of the NIST database and the second approach was calculating linear retention indices and comparing the result with literature values. The two major peaks in the chromatogram could be reliably identified using the NIST database as acetone (3.54 min retention time) and nopinone (25.34 min retention time). The identification of both peaks was also verified by comparison of the mass spectra with the spectra obtained for the calibration of the GC-MS detector.

Nopinone had been previously identified as a major product of the $\beta$-pinene ozonolysis (Grosjean et al., 1993; Hakola et al., 1994) in the gas phase (Lee et al., 2006; Winterhalter et al., 2000) and also in the particle phase (Yokouchi and Ambe, 1985; Jaoui and Kamens, 2003a). Also acetone was found as a major product formed in the reaction of $\beta$-pinene with ozone (Orlando et al., 2000; Larsen et al., 2001; Wisthaler et al., 2001; Jaoui and Kamens, 2003b). However the acetone in these studies was only measured in the gas phase not in the particle phase. It is unlikely that the acetone partitions from the gas phase into the SOA due to its high vapor pressure. Investigations of the $\beta$-pinene SOA with thermal desorption system coupled to a gas chromatograph isotope ration mass spectrometer (GC-IRMS) show that the acetone found in these studies is a thermal decomposition product of SOA compounds (Fisseha et al., 2009). Based on the $\delta^{13} \mathrm{C}$ of the acetone Fisseha et al. (2009) conclude that the acetone may be a tracer for higher order oxygenated products or oligomers. Since the volatile and semi-volatile compounds of the particles collected with the ACM were evaporated from the collector at $225^{\circ} \mathrm{C}$ it is reasonable to assume that the acetone measured with the ACM GC-MS is due to a thermal breakdown of higher molecular compounds.

Comparing our results to literature data on the composition of $\beta$-pinene SOA formed through both $\mathrm{O}_{3}$ and $\mathrm{OH}$ oxidation we additionally assigned the following substances to peaks in the chromatogram: bicyclo[3,1,1]hept3-ene-2-one, bicyclo[3,1,1]heptane-2-carboxaldehyde (also known as myrtanal), myrtenol, 1-hydroxinopinone, 3oxonopinone (also known as 3-oxo-pina ketone) and 3,7dihydroxynopinone. In Table 2 the structure, molecular weight, the major ion fragments, and the retention time of these compounds are summarized. To strengthen the identification of myrtenol and myrtanal the retention index (RI) of each compound was calculated and compared to literature data. The linear retention indices for the identified compounds were calculated and are summarized in Table 3 . The linear retention indices for myrtanal and myrtenol reported in the literature correspond well with the index determined in this work. In previous studies myrtenol was only detected in the gas phase. In this work the presence of myrtenol was measured for the first time also in the particle phase. However further studies of the vapor pressure and the partitioning of myrtenol are necessary to clarify if the presence of myrtenol in the particle phase is due to gas-particlepartitioning in the chamber. 
Table 2. Retention time, structure, molecular weight, and $\mathrm{m} / \mathrm{z}$ of the major ion fragments of the identified products in the $\beta$-pinene ozonolysis experiment listed in the order of ascending retention time.

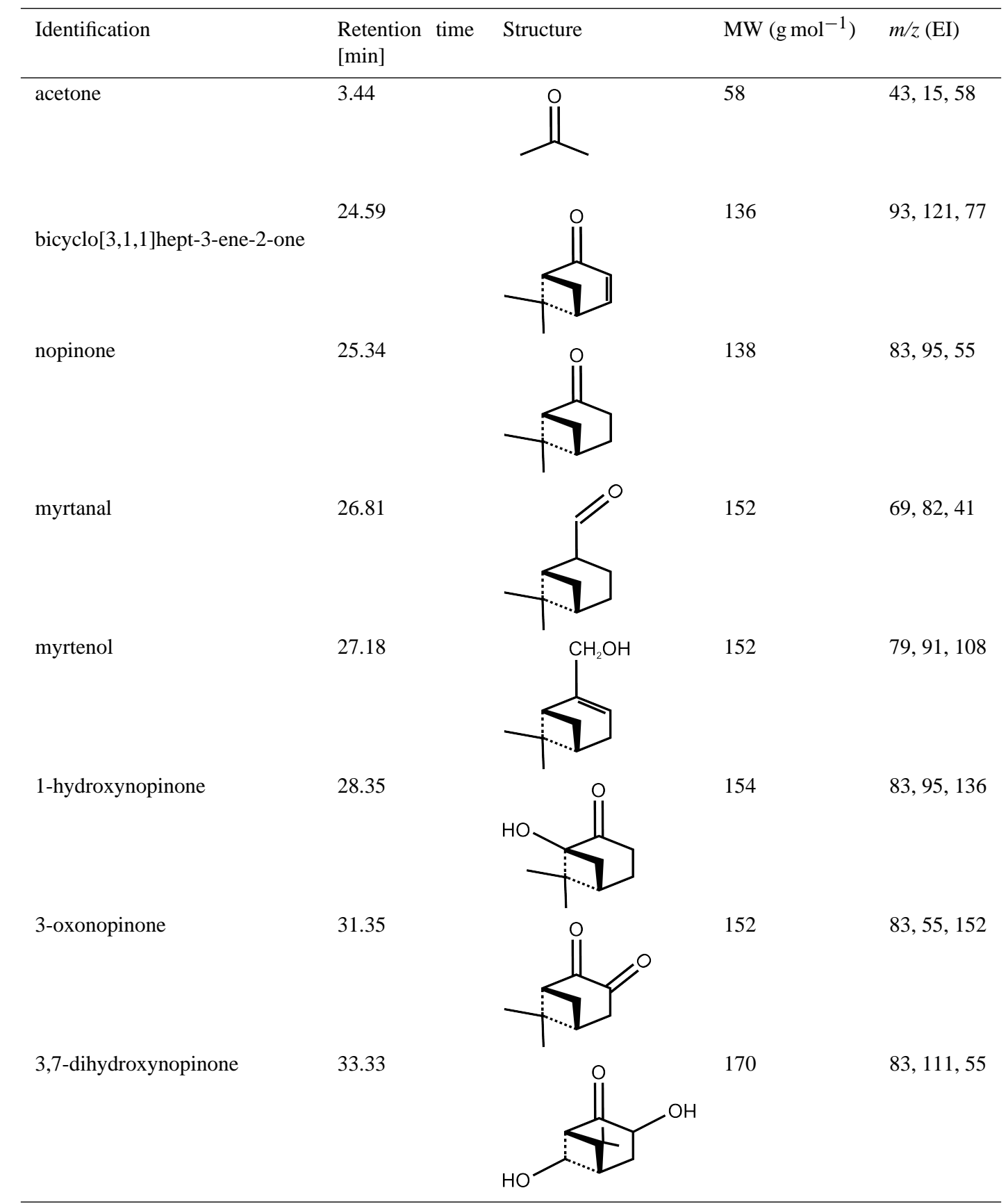

\subsection{Total mass measured by ACM GC-MS}

In Fig. 6 the total mass measured for each sample with the ACM GC-MS was normalized to the collector mass loading derived from the SMPS measurements. The collector mass loading was determined using Eq. (1). Note that an average density of $1.2 \mathrm{~g} \mathrm{~cm}^{-3}$ was used for the SOA. The mass fraction measured with the ACM GC-MS was $11 \%$ at the be- ginning of the experiment and decreased during the first day to $6 \%$ and was nearly constant for the next two days. With this current set up it can not be clearly distinguished between losses in the ACM and in the GC/MS-FID. However in part the low (6-11\%) recovery of SOA mass with the ACM GCMS can be explained by the known compound detection limitations of the GC-MS system for higher oxygenated products which are also produced in the $\beta$-pinene ozonolysis. 


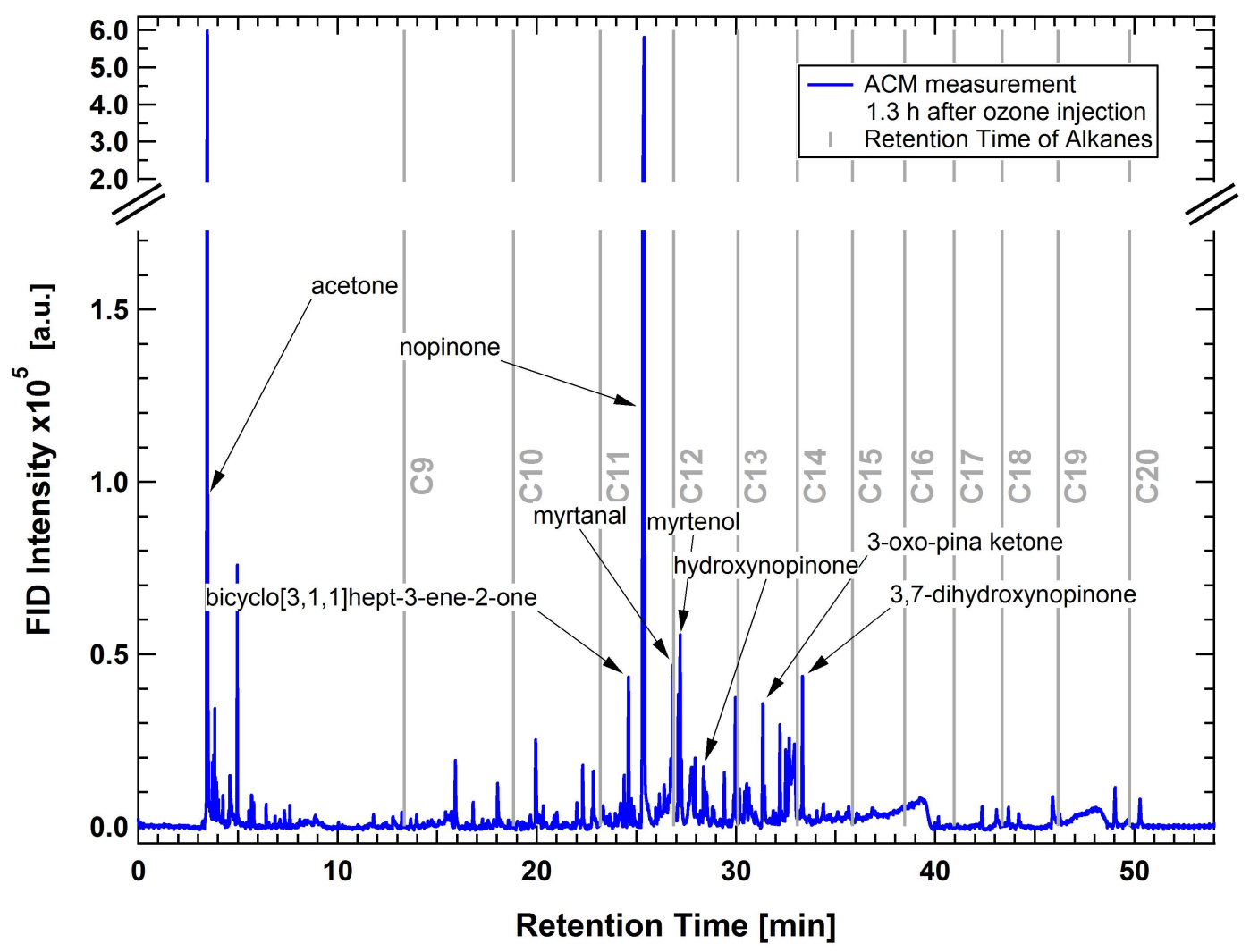

Fig. 5. ACM GC-FID chromatograms measured at the beginning of the experiment. The grey vertical bars indicate the retention times of the homologous series of alkanes from the GC/MS-FID calibration which were used to calculate linear retention indices

Table 3. Comparison of determined linear retention indices of the identified products with literature values.

\begin{tabular}{llll}
\hline $\begin{array}{l}\text { Compound } \\
\text { name }\end{array}$ & $\begin{array}{l}\text { RI } \\
\text { this work }\end{array}$ & $\begin{array}{l}\text { RI other studies } \\
\text { (type of column) }\end{array}$ & Reference \\
\hline myrtanal & 1198 & 1180 (HP-5MS) & $\begin{array}{l}\text { Papandreou et al. } \\
(2002)\end{array}$ \\
myrtenol & 1209 & 1202 (DB-5MS) & $\begin{array}{l}\text { Kowalski and Wol- } \\
\text { ski (2005) } \\
\text { Wang et al. (2005) }\end{array}$ \\
\hline
\end{tabular}

Furthermore the GC-MS technique is limited with regard to measuring high molecular weight compounds. The evidence for oligomer formation in SOA from the photooxidation and ozonolysis of $\alpha$-pinene were measured during different smog chamber studies (Gao et al., 2004; Baltensperger et al., 2005; Müller et al., 2008). Baltensperger et al. (2005) additionally found increasing abundances of high molecular weight compounds (up to $1000 \mathrm{amu}$ ) with increasing aging time of the SOA. They also estimated that after $20 \mathrm{~h}$ of aging about $50 \%$ of the particle mass consisted of oligomers. Under the assumption that in the $\beta$-pinene ozonolysis also oligomerization occurred these high molecular compounds in the SOA would not have been detected by the GC-MS system.

As an example also the time series of the fractional abundances of nopinone (green triangles) and 1-hydroxynopinone (red squares) are shown in Fig. 6. While the relative abundances of nopinone decreased continuously over the course of the experiment the relative abundances of 1hydroxynopinone increased steadily. This shows that the ACM GC-MS system is also capable of studying changes in aerosol composition.

\subsection{Intercomparison of ACM GC-MS and filter samples}

During the chamber experiment filter samples were collected in parallel to the ACM measurements. All filter samples were taken using a front and a back quartz filter. All front and back filter samples were analyzed using a Agilent 6890 (1530A) Gas Chromatograph equipped with a Rtx1 (105 m $\times 0.32 \mathrm{~mm}$ ID, film thickness $3 \mu \mathrm{m}$ ) (Restek Corporation, Bad Homburg, Germany) fused sillica column and a flame ionization detector (FID). The GC was connected to a custom built cryosampling thermal desorption system (GERSTEL GmbH \& Co. KG, Mülheim an der Ruhr, Germany) for the preconcentration of VOCs. The setup and its use for filter analysis are described in detail by Iannone et al. (2007) and Fisseha et al. (2009), respectively. Note that the temperature of the thermal desorption system was set to $225^{\circ} \mathrm{C}$, 


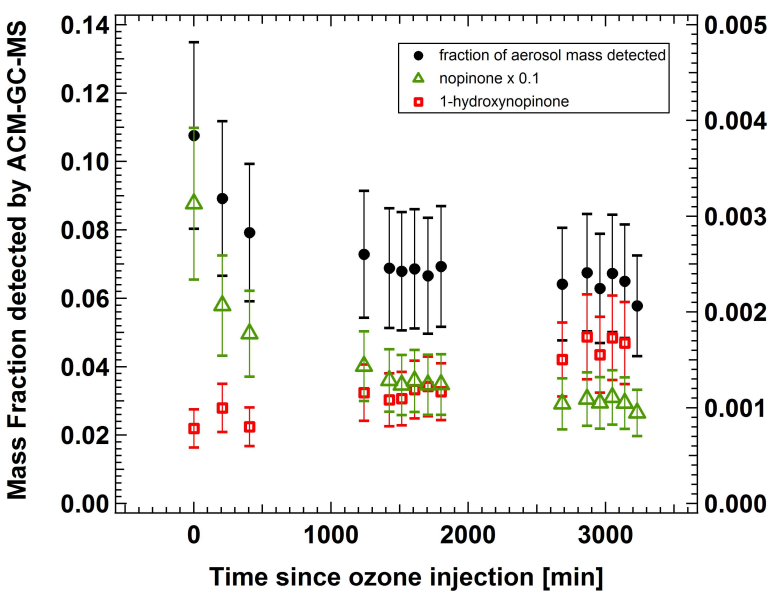

Fig. 6. Time series of the fraction of the particle mass detected by the ACM GC-MS (black circles). Also as an example the time series of the fractional abundances of nopinone (green triangles) and 1-hydroxynopinone (red squares) are shown. Note that the temporal trend for both compounds are different indicating a change in chemical composition of the SOA.

according to the desorption temperature of the ACM collector. The total amount of nopinone in the SOA sampled with the filters was determined. In Fig. 7 the total nopinone mass measured with the filter samples is compared to the total nopinone mass measured with the ACM GC-MS. The total nopinone mass measured on the filters was corrected for back filters (BF), particle volume distribution (PVD) and nopinone distribution (ND) on the filter. The BF correction accounts for nopinone gas phase adsorption on the filters. The BF corrections for all samples were in the range of $0.024 \mu \mathrm{g}$ to $0.049 \mu \mathrm{g}$. The PVD correction is due to the different size ranges of the particles collected with ACM and filters. During the $\beta$-pinene ozonolysis experiment the particles grew such that a significant fraction of the particles had a diameter larger than $500 \mathrm{~nm}$ when lens transmission becomes a limiting factor of mass transfer into the ACM. The particles with diameter larger than $500 \mathrm{~nm}$ contribute to the total nopinone mass collected with the filters only. Therefore, the filter nopinone mass corresponding to particles $<500 \mathrm{~nm}$ was determined by using the SMPS data. Assuming an aerosol composition independent of size, the filter results were thus corrected for the overestimated nopinone mass. The nopinone mass on the filter was overestimated by a factor ranging for the different samples collected during the experiment from 1.33 to 1.77 compared to the ACM nopinone mass. For the filter analysis described in detail by Fisseha et al. (2009) a $3 \mathrm{~mm}$ circular piece was midmost cut out from the whole filter. The total amount of sampled nopinone was derived considering the same concentration on the whole filter. However the distribution of collected particles on the filters was not homogeneous. Profiles of the nopinone concentration on the filters were determined and showed higher values in the center decreasing to the edges of the sampling area. A correction

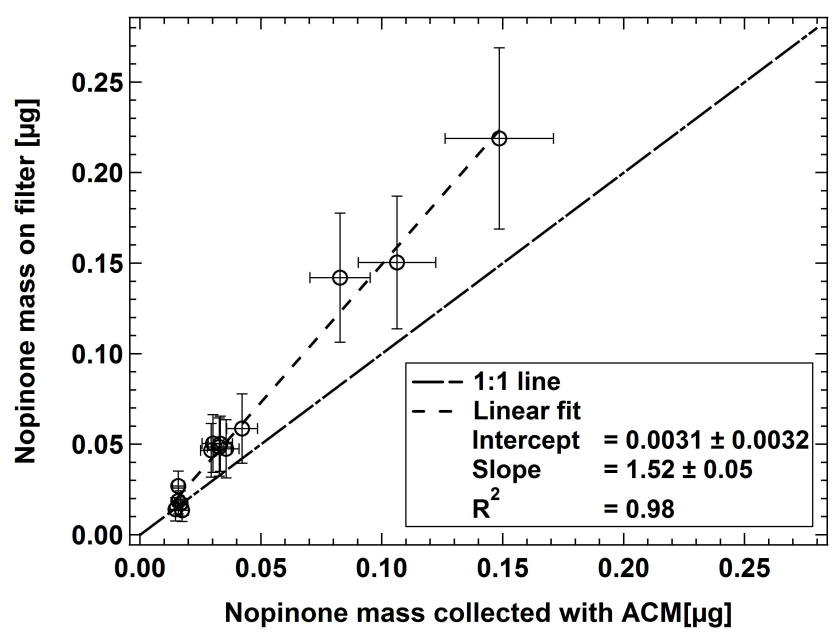

Fig. 7. Correlation between the corrected (see text) total nopinone mass sampled with filters and the total nopinone mass measured with the ACM GC-MS.

owing to the inhomogeneity of particle loading across the filter was done accounting for the overestimated nopinone concentration on the cut out filter piece. Due to the inhomogeneity of particle loading the total nopinone mass on each filter was overestimated by a factor of 1.36 .

Figure 7 shows the correlation between the total nopinone mass measured with ACM GC-MS and the corrected nopinone mass measured with the filter samples. The linear fit applied to the data points shows that the ACM GC-MS is underestimating the results of the filter measurements for some samples collected during the experiment. Furthermore the disagreement between both types of measurements occurs and increases with increasing total nopinone mass. For total nopinone masses below $30 \mathrm{ng}$ both measurements agree very well. In the mass range of $30 \mathrm{ng}$ to $50 \mathrm{ng}$ the filter results are generally higher than the ACM GC-MS results but agree within the margin of error. However at high masses over $80 \mathrm{ng}$ the ACM GC-MS clearly underestimates the nopinone mass compared to the results obtained with the filter measurements. Note that in Fig. 7 only the nopinone mass is shown and that the corresponding total aerosol mass was significantly higher. The aerosol mass concentration in the chamber corresponding to the measurements of the nopinone mass above $80 \mathrm{ng}$ were between $650 \mathrm{\mu g} \mathrm{m}^{-1}$ and $830 \mu \mathrm{g} \mathrm{m}^{-1}$. This corresponds for a sampling time of $60 \mathrm{~min}$ to a total ACM collector mass loading of 3.5 to $4 \mu \mathrm{g}$. For the total nopinone mass ranging from $30 \mathrm{ng}$ to $50 \mathrm{ng}$ the corresponding total ACM collector mass loading was between $2 \mu \mathrm{g}$ and $2.5 \mu \mathrm{g}$. For the measurements of the total nopinone mass below $30 \mathrm{ng}$ the total ACM collector mass loading was between $1.15 \mu \mathrm{g}$ and $1.4 \mu \mathrm{g}$. The characterization experiments were conducted with a maximum aerosol loading of the ACM collector of $0.1 \mu \mathrm{g}$. Since linearity was not confirmed for very high total aerosol mass loadings on the ACM collector non linear sampling and/or desorption artifacts could have 


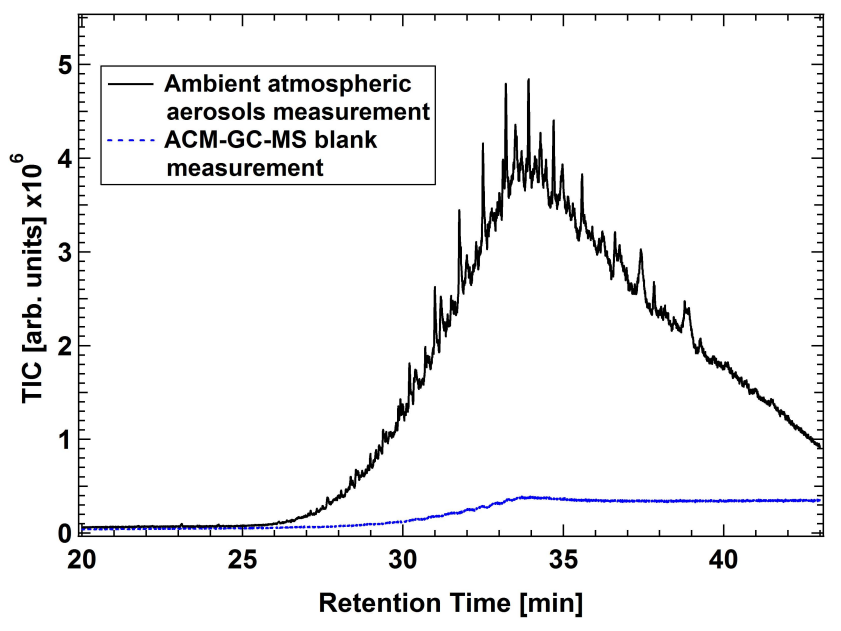

Fig. 8. ACM GC-MS chromatogram of ambient aerosol particles sampled at the Aerodyne Research, Inc. laboratory in Billerica, USA. The blue curve is the blank measurement done after the ambient aerosol measurement. The rise in the baseline is due to typical GC column bleeding.

an effect. However the agreement between ACM GC-MS and filter measurements for nopione especially for the lower mass range is very good. In this lower mass range where most chamber studies are usually conducted the results of the ACM GC-MS for a tracer compound such as nopinone are in agreement with the filter measurements and are quantitatively reproducible.

\subsection{Ambient aerosol measurement with the ACM GC-MS}

The first ambient air measurements with the ACM GC-MS were conducted in an urban enviroment at the Aerodyne Research, Inc. laboratory in Billerica, USA. The ACM GC-MS was connected to a sampling line through which ambient atmospheric aerosol could be collected from the roof of the laboratory. In addition an Aerodyne Aerosol Mass Spectrometer (AMS) was measuring in parallel to the ACM GC-MS sampling from the same sampling line. Particle samples were taken regularly over the course of several days with the ACM GC-MS system. The collection time for each sample was $6 \mathrm{~h}$. The collection temperature was $-30^{\circ} \mathrm{C}$. Afterwards the collected particles were desorbed at a temperature of $260^{\circ} \mathrm{C}$ for 6 min. In total 15 samples were taken over the course of the experiment. An example chromatogram from one of the air samples is shown in Fig. 8. Peaks for individual compounds lie on top of a broad background of unresolved complex mixtures which is indicative of hydrocarbon-like organic aerosol (HOA). Similar chromatograms from urban samplings were also observed by Williams et al. (2006) with the Thermal Desorption Aerosol GC/MS-FID (TAG) system. The blue trace in Fig. 8 shows a typical blank measurement of the ACM GC-MS which were taken regularly between the ambient air sampling. The blanks were performed with particle-

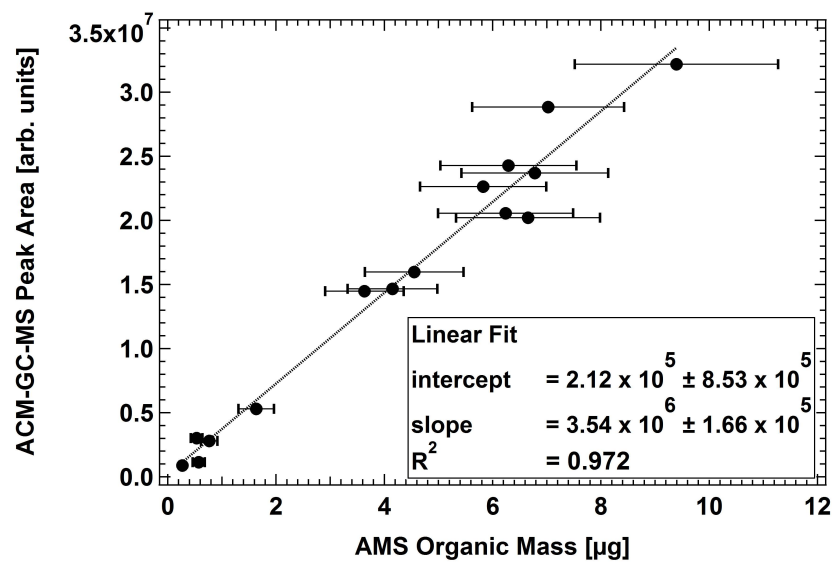

Fig. 9. Comparison of the signal measured with the ACM GC-MS to organic mass measured with a co-located AMS.

free filtered ambient air entering the ACM GC-MS. The rise in the signal in the blank measurement beginning at $30 \mathrm{~min}$ retention time is due to $\mathrm{GC}$ column bleeding.

As a first analysis the ACM GC-MS total signal measured for the ambient aerosol particle samples was compared to the total organic mass measured with the AMS. The ACM GCMS signal was calculated by integrating the total area under the chromatogram. Figure 9 shows the comparison of the ACM GC-MS signal to the total organic mass measured with the AMS during the same time period. The mass loadings measured with the AMS varied between 10 and $300 \mu \mathrm{g} \mathrm{m}^{-3}$. The correlation between the two sets of data is linear with a high correlation coefficient, indicating that the overall ACM GC-MS measurements are representative of the ambient organic aerosol mass loading.

\section{Conclusions}

A new technique for quasi on-line compound specific measurements of organic aerosol was developed. The Aerosol Collection Module (ACM) samples, collects and transfers atmospheric aerosol particles to a gas phase detector. Particles are efficiently sampled in the $70-500 \mathrm{~nm}$ size range by focusing the particles into a particle beam which passes a vacuum chamber and impacts onto a cooled collection surface. The sampling in a high vacuum environment allows the study of only the particle phase of the aerosols without interference of the gas phase constituents. The volatile and semi-volatile organic compounds are then efficiently transferred via thermal desorption into a coupled gas phase detector.

The ACM coupled to a GC/MS-FID (ACM GC-MS) was used to determine important instrumental characteristics of the ACM. The particle collection, desorption and transfer efficiency of laboratory generated octadecane test aerosols were determined. The total octadecane mass provided for sampling with the ACM GC-MS was determined with a SMPS measuring in parallel to the ACM GC-MS. The octadecane particles were collected, desorbed and transferred 
with an efficiency of $100 \%$. The recovery rate of $100 \%$ was confirmed for an interval of desorption and valve array temperatures ranging from $150^{\circ} \mathrm{C}$ to $270^{\circ} \mathrm{C}$. For both characterization experiments the ACM GC-MS response was linear in response to the measured octadecane mass.

The new sampling and characterization technique of the ACM GC-MS was also used in its first application in a study of the formation of SOA from the ozone oxidation of $\beta$ pinene in the Jülich aerosol chamber. During the $\beta$-pinene ozonolysis experiment 16 SOA samples over the duration of $57 \mathrm{~h}$ were successfully collected and measured with the ACM GC-MS. Using the ACM GC-MS several products of the $\beta$-pinene ozonolysis could be identified in the particle phase. These compounds were bicyclo[3,1,1]hept-3-ene-2one, nopinone, myrtanal, myrtenol, 1-hydroxynopinone, 3oxonopinone, and 3,7-dihydroxynopinone. The presence of myrtenol was observed for the first time also in the particle phase.

Comparison of the total nopinone mass between filter samples and the ACM GC-MS show a good agreement for total aerosol masses below $290 \mu \mathrm{g}$. The ACM GC-MS system efficiently collects particles in the size range of 70 $500 \mathrm{~nm}$ and transfers organic compounds via thermal desorption into a gas phase detector with quantitatively reproducible results for nopinone. Nopinone is proposed as possible atmospheric tracer for secondary organic aerosol formation from monoterpenes. Therefore the ACM GC-MS can contribute to the understanding of formation processes of aerosols and source apportionment studies of aerosols.

The first ambient atmospheric aerosol measurement indicates that the ACM-GC-MS system is also capable of linear, quantitative measurements of individual organic compounds in ambient aerosol mass loadings.

In future works the analytical potential of the ACM will be further explored by coupling the ACM to PTR-MS and GCIRMS detectors. These set-up will be utilized in chamber and field studies to determine aerosol sources, aerosol transformations, and the identification of organic marker compounds in ambient atmospheric aerosols. Due to its low sampling flow the ACM is especially suited for chamber studies where the sampling volume is limited and high volume collectors can not be used.

Further technical improvements of the ACM including an online derivatization system in the collection section and the aerosol enrichment of the sampling volume using a virtual impactor in front of the ACM inlet will be explored.

Acknowledgements. We thank Paul Ziemann and Brent Williams for discussions and helpful suggestions concerning coating materials. Aerodyne and MIT would also like to thank the US EPA (grant number RD-83107701-0) and the US DoE (grant number DE-FG02-05ER84269) for initial instrument development support.

Edited by: J.-P. Putaud

\section{References}

Atkinson, R.: Gas-Phase Tropospheric Chemistry of Volatile Organic Compounds: 1. Alkanes and Alkenes, J. Phys. Chem. Ref. Data, 26(2), 215-290, 1997.

Atkinson, R. and Arey, J.: Gas-phase tropospheric chemistry of biogenic volatile organic compounds: a review, Atmos. Environ. 37, 197-219, 2003.

Baltensperger, U., Kalberer, M., Dommen, J., Paulsen, D., Alfarra, M. R., Coe, H., Fisseha, R., Gascho, A., Gysel, M., Nyeki, S., Sax, M., Steinbacher, M., Prevot, A. S. H., Sjogren, S., Weingartner, E., and Zenobi, R.: Secondary organic aerosols from anthropogenic and biogenic precursors, Faraday Discuss., 130, 265-278, 2005.

Canagaratna, M. R., Jayne, J. T., Jimenez, J. L., Allan, J. D., Alfarra, M. R., Zhang, Q., Onasch, T. B., Drewnick, F., Coe, H., Middlebrook, A., Delia, A., Williams, L. R., Trimborn, A. M., Northway, M. J., DeCarlo, P. F., Kolb, C. E., Davidovits, P., and Worsnop, D. R.: Chemical and Microphysical Characterization of Ambient Aerosols with the Aerodyne Aerosol Mass Spectrometer, Mass Spectrom. Rev., 26, 185-222, 2007.

Fisseha, R., Spahn, H.,Wegener, R., Hohaus, T., Brasse, G., Wissel, H., Tillmann, R., Wahner, A., Koppmann, R., and KiendlerScharr, A.: Stable carbon isotope composition of secondary organic aerosol from beta-pinene oxidation, J. Geophys. Res., 114, D02304, doi:10.1029/2008JD011326, 2009.

Gao, S., Keywood, M., Ng, N. L., Surratt, J., Varutbangkul, V., Bahreini, R., Flagan, R. C., and Seinfeld, J. H.: Lowmolecularweight and oligomeric components in secondary organic aerosol from the ozonolysis of cycloalkenes and alphapinene, J. Phys. Chem. A, 108(46), 10147-10164, 2004.

Goldstein, A. H. and Galbally, I. E.: Known and Unexplored Organic Constituents in the Earth's Atmosphere, Environ. Sci. Technol., 41(5), 1514-1521, 2007.

Grosjean, D., Williams, E. L., Grosjean, E., Andino, J. M., and Seinfeld, J. H.: Atmospheric oxidation of biogenic hydrocarbons - reaction of ozone with beta-pinene, d-limonene and transcaryophyllene, Environ. Sci. Technol., 27(13), 2754-2758, 1993.

Guenther, A., Hewitt, C. N., Erickson, D., Fall, R., Geron, C., Graedel, T., Harley, P., Klinger, L., Lerdau, M., Mckay, W. A., Pierce, T., Scholes, B., Steinbrecher, R., Tallamraju, R., Taylor, J., and Zimmerman, P.. A global model of natural volatile organic compound emissions, J. Geophys. Res., 100, 8873-8892, 1995.

Hakola, H., Arey, J., Aschmann, S. M., and Atkinson, R.: Product formation from the gas-phase reactions of oh radicals and $\mathrm{O} 3$ with a series of monoterpenes, J. Atmos. Chem., 18(1), 75-102, 1994.

Hallquist, M., Wenger, J. C., Baltensperger, U., Rudich, Y., Simpson, D., Claeys, M., Dommen, J., Donahue, N. M., George, C., Goldstein, A. H., Hamilton, J. F., Herrmann, H., Hoffmann, T., Iinuma, Y., Jang, M., Jenkin, M. E., Jimenez, J. L., Kiendler-Scharr, A., Maenhaut, W., McFiggans, G., Mentel, Th. F., Monod, A., Prévôt, A. S. H., Seinfeld, J. H., Surratt, J. D., Szmigielski, R., and Wildt, J.: The formation, properties and impact of secondary organic aerosol: current and emerging issues, Atmos. Chem. Phys., 9, 5155-5236, doi:10.5194/acp-95155-2009, 2009.

Hamilton, J. F., Webb, P. J., Lewis, A. C., Hopkins, J. R., Smith, S., and Davy, P.: Partially oxidised organic components in urban 
aerosol using GCXGC-TOF/MS, Atmos. Chem. Phys., 4, 12791290, doi:10.5194/acp-4-1279-2004, 2004.

Iannone, R., Koppmann, R., and Rudolph, J.: A technique for atmospheric measurements of stable carbon isotope ratios of isoprene, methacrolein, and methyl vinyl ketone, J. Atmos. Chem., 58(3), 181-202, 2007.

Jaoui, M. and Kamens, R. M.: Gaseous and particulate oxidation products analysis of a mixture of alpha-pinene plus betapinene/o-3/air in the absence of light and alpha-pinene plus betapinene/nox/air in the presence of natural sunlight, J. Atmos. Chem., 44(3), 259-297, 2003a.

Jaoui, M. and Kamens, R. M.: Mass balance of gaseous and particulate products from beta-pinene/o-3/air in the absence of light and beta-pinene/nox/air in the presence of natural sunlight, J. Atmos. Chem., 45(2), 101-141, 2003 b.

Jayne, J. T., Leard, D. C., Zhang, X. F., Davidovits, P., Smith, K. A., Kolb, C. E., and Worsnop, D. R.: Development of an aerosol mass spectrometer for size and composition analysis of submicron particles, Aerosol Sci. Technol., 33(1-2), 49-70, 2000.

Kesselmeier, J. and Staudt, M.: Biogenic volatile organic compounds (voc): An overview on emission, physiology and ecology, J. Atmos. Chem., 33, 23-88, 1999.

Kowalski, R. and Wolski, T.: The chemical composition of essential oils of silphium perfoliatum 1., Flavour Frag. J., 20(3), 306-310, 2005.

Larsen, B. R., Di Bella, D., Glasius, M., Winterhalter, R., Jensen, N. R., and Hjorth, J.: Gas-phase oh oxidation of monoterpenes: Gaseous and particulate products, J. Atmos. Chem., 38(3), 231276, 2001.

Lee, A., Goldstein, A. H., Keywood, M. D., Gao, S., Varutbangkul, V., Bahreini, R., Ng, N. L., Flagan, R. C., and Seinfeld, J. H.: Gas-phase products and secondary aerosol yields from the ozonolysis of ten different terpenes, J. Geophys. Res., 111, D07302, doi:10.1029/2005JD006437, 2006.

Liu, P., Ziemann, P. J., Kittelson, D. B., and McMurry, P. H.: Generating particle beams of controlled dimensions and divergence .1. theory of particle motion in aerodynamic lenses and nozzle expansions, Aerosol Sci. Technol., 22(3), 293-313, 1995a.

Liu, P., Ziemann, P. J., Kittelson, D. B., and McMurry, P. H.: Generating particle beams of controlled dimensions and divergence 2 . experimental evaluation of particle motion in aerodynamic lenses and nozzle expansions, Aerosol Sci. Technol., 22(3), 314-324, 1995b.

Liu, P. S. K., Deng, R., Smith, K. A., Williams, L. R., Jayne, J. T., Canagaratna, M. R., Moore, K., Onasch, T. B., Worsnop, D. R., and Deshler, T.: Transmission efficiency of an aerodynamic focusing lens system: Comparison of model calculations and laboratory measurements for the aerodyne aerosol mass spectrometer, Aerosol Sci. Technol., 41(8), 721-733, 2007.

McMurry, P. H.: A review of atmospheric aerosol measurements, Atmos. Environ., 34, 1959-1999, 2000.

Mentel, T. and Wahner, A.: A large reaction chamber for nighttime atmospheric chemistry: design and characteristics of the reaction chamber, Berichte des Forschungszentrums Jülich GmbH, 3196, 1996.
Müller, L., Reinnig, M.-C., Warnke, J., and Hoffmann, Th.: Unambiguous identification of esters as oligomers in secondary organic aerosol formed from cyclohexene and cyclohexene $/ \alpha$ pinene ozonolysis, Atmos. Chem. Phys., 8, 1423-1433, doi:10.5194/acp-8-1423-2008, 2008

Orlando, J. J., Nozire, B., Tyndall, G. S., Orzechowska, G. E., Paulson, S. E., and Rudich, Y.: Product studies of the oh- and ozone-initiated oxidation of some monoterpenes, J. Geophys. Res., 105(D9), 11561-11572, 2000.

Papandreou, V., Magiatis, P., Chinou, I., Kalpoutzakis, E., Skaltsounis, A. L., and Tsarbopoulos, A.: Volatiles with antimicrobial activity from the roots of greek paeonia taxa, J. Ethnopharmacology, 81(1), 101-104, 2002.

Rudich, Y., Donahue, N. M., and Mentel, T. F.: Aging of organic aerosol: Bridging the gap between laboratory and field studies, Annu. Rev. Phys. Chem., 58(1), 321-352, 2007.

Tobias, H. J., Kooiman, P. M., Docherty, K. S., and Ziemann, P. J.: Real-time chemical analysis of organic aerosols using a thermal desorption particle beam mass spectrometer, Aerosol Sci. Tech., 33, 170-190, 2000.

Turpin, B. J., Saxena, P., and Andrews, E.: Measuring and simulating particulate organics in the atmosphere: problems and prospects, Atmos. Environ., 34(18), 2983-3013, 2000.

Wang, Y., Finn, C., and Qian, M. C.: Impact of growing environment on chickasaw blackberry (rubus 1.) aroma evaluated by gas chromatography olfactometry dilution analysis, J. Agric. Food Chem., 53(9), 3563-3571, 2005.

Weber, R. J., Orsini, D., Daun, Y., Lee, Y.-N., Klotz, P., and Brechtel, F.: A particle-into-liquid collector for rapid measurements of aerosol chemical composition, Aerosol Sci. Tech., 35, 718-727, 2001.

Williams, B., Goldstein, A., Kreisberg, N., and Hering, S.: An insitu instrument for speciated organic composition of atmospheric aerosols: thermal desorption aerosol gc/ms-fid (TAG), Aerosol Sci. Tech., 40(8), 627-638, 2006.

Winterhalter, R., Neeb, P., Grossmann, D., Kolloff, A., Horie, O., and Moortgat, G.: Products and mechanism of the gas phase reaction of ozone with beta-pinene, J. Atmos. Chem., 35, 165-197, 2000 .

Wisthaler, A., Jensen, N., Winterhalter, R., Lindinger, W., and Hjorth, J.: Measurements of acetone and other gas phase product yields from the oh-initiated oxidation of terpenes by protontransfer- reaction mass spectrometry (ptr-ms), Atmos. Environ., 35, 6181-6191, 2001.

Yokouchi, Y. and Ambe, Y.: Aerosols formed from the chemical reaction of monoterpenes and ozone, Atmos. Environ., 19(8), 1271-1276, 1985.

Zhang, X., Smith, K. A., Worsnop, D. R., Jimenez, J. L., Jayne, J. T., Kolb, C. E.: A numerical characterization of particle beam collimation by an aerodynamic lens-nozzle system. Part I: An individual lens or nozzle, Aerosol Sci, Tech., 36, 617-631, 2002.

Zhang, X., Smith, K. A., Worsnop, D. R., Jimenez, J. L., Jayne, J. T., Kolb, C. E., Morris, J., Davidovits, P.: Characterization of particle beam collimation. Part II: Integrated aerodynamic lensnozzle system, Aerosol Sci. Tech., 38, 619-638, 2004b. 